\title{
Pterional craniotomy via a transcavernous approach for the treatment of low-lying distal basilar artery aneurysms
}

\section{Stephen L. Nutik, M.D., Ph.D.}

Department of Neurosurgery, Kaiser Foundation Hospital, Redwood City, California

Object. The author describes a surgical procedure in which pterional craniotomy is performed via a transcavernous approach to treat low-lying distal basilar artery (BA) aneurysms. This intradural procedure is compared with the extradural procedure described by Dolenc, et al.

Methods. The addition of a transcavernous exposure to the standard pterional intradural transsylvian approach allows a lower exposure of the distal BA behind the dorsum sellae. The technical steps involved in this procedure are as follows: 1) removal of the anterior clinoid process; 2 ) entry into the cavernous sinus medial to the third nerve; 3 ) packing of the venous channels of the cavernous sinus lying between the carotid artery and the pituitary gland to open this space; 4) removal of the posterior clinoid process and the portion of the dorsum sellae that is exposed from within the cavernous sinus; and 5) removal of the exposed dura mater to obtain additional exposure of the perimesencephalic cistern. Eight cases of aneurysms of the distal BA are presented to illustrate how this approach can help in their surgical treatment.

Conclusions. Using the standard pterional approach, these distal BA aneurysms were found to be either too low relative to the posterior clinoid process for adequate exposure or there was insufficient room for temporary clipping of the BA proximal to the lesion. The addition of a transcavernous exposure eliminated these technical problems and aneurysm clipping could be accomplished in each case.

Key Words * basilar artery aneurysm * posterior clinoid process * pterional approach * surgical approach

The pterional transsylvian approach is a standard procedure for the treatment of distal basilar artery (BA) aneurysms.[15] However, aneurysms located below the level of the posterior clinoid process may prove to be inaccessible when using this route.[13,15] In these cases, a lower exposure can be achieved by removal of the posterior clinoid process.[15] Dolenc, et al.,[4] described a modification of the transsylvian approach that provides even greater proximal exposure of the distal BA. Using their technique, the posterior clinoid process and a portion of the dorsum sellae are removed after exposing them via the cavernous sinus. A preliminary step in the transcavernous procedure is the removal of the anterior clinoid process, which Dolenc, et al., describe as an extradural modification of the standard pterional craniotomy. However, the same transcavernous exposure can be readily obtained using a 
completely intradural procedure following a standard pterional craniotomy. The following is a description of this intradural technique and a discussion of its advantages over the partially extradural approach described by Dolenc, et al. Eight cases of low-lying distal BA aneurysms are presented to illustrate the usefulness of the procedure.

\section{CLINICAL MATERIAL AND METHODS}

\section{Patient Population}

Eight cases of patients with low-lying aneurysms of the distal BA are described. In each case, the aneurysm was located too low to be clipped via the standard pterional approach and additional exposure was necessary. This exposure was obtained by the transcavernous removal of the posterior clinoid process and ipsilateral dorsum sellae. In four of the cases the patient had a BA bifurcation aneurysm and in three the patient had a BA/superior cerebellar artery (SCA) aneurysm. The angiographic appearance of the aneurysms is shown in Fig. 1 and some clinical features are given in Table 1.

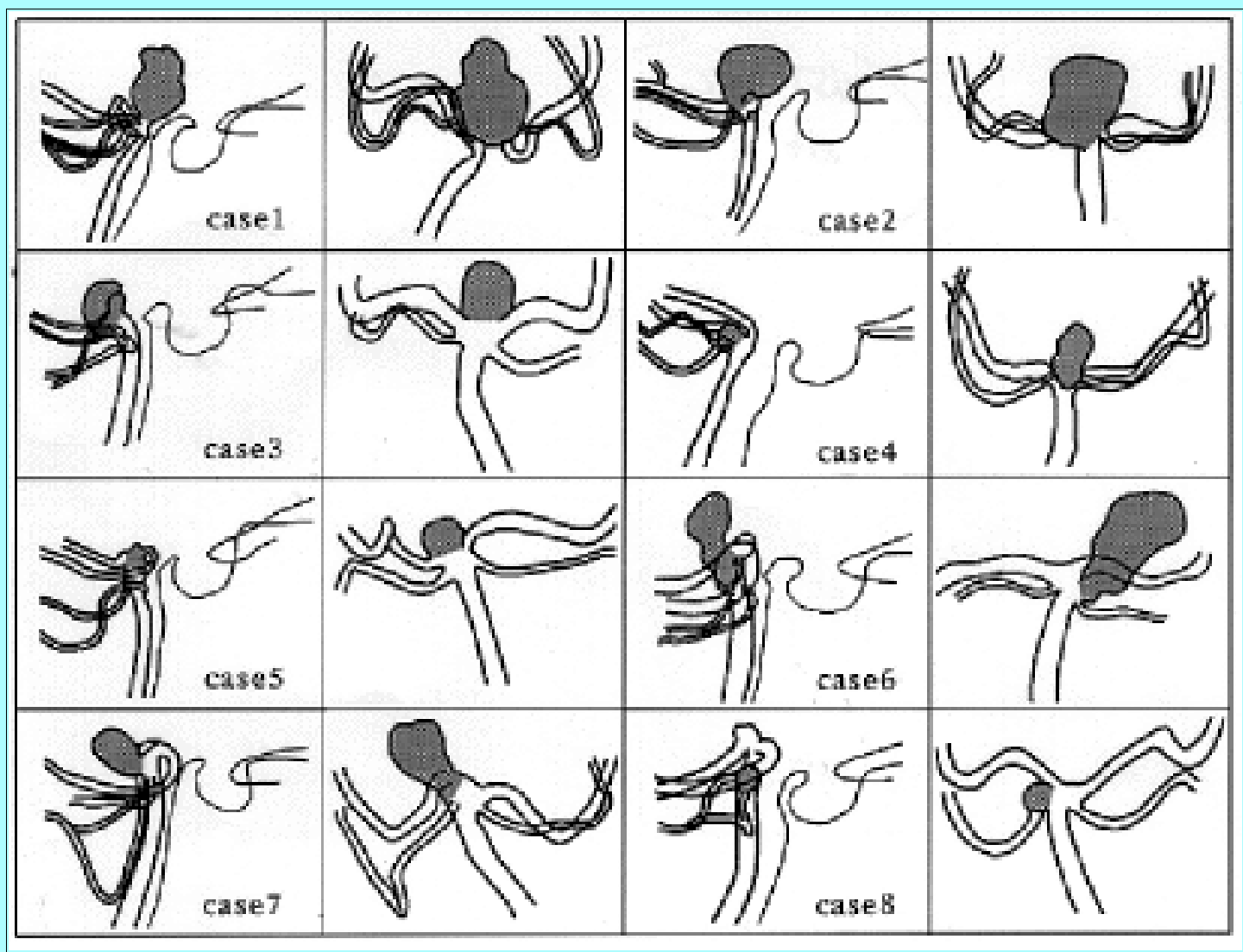

Fig. 1. Tracings of lateral and anteroposterior angiograms obtained in the eight cases showing the BA and origins of the SCA and posterior cerebral artery. The aneurysms are shaded. The outline of the sella turcica and anterior clinoid process has also been traced on the lateral views.

Four patients presented with subarachnoid hemorrhage (Cases 1, 3, 5, and 6) and in three patients the BA aneurysm was found incidentally during angiography for another suspected aneurysm (Cases 2, 4, and 8). The final patient presented with dizziness; radiological investigation revealed multiple aneurysms, the most significant of which was large, partially thrombosed, and originating at the junction of the BA and right SCA (Case 7). In both patients harboring a large SCA aneurysm (Cases 6 and 7), the dome of the aneurysm extended above and posterior to the ipsilateral posterior cerebral artery. 
CLINICAL FIND NGS IN EIGHT PATIENTS WITH LOW-LYING BA ANEURVSMS*

\begin{tabular}{|c|c|c|c|c|c|c|}
\hline \multirow{2}{*}{$\begin{array}{l}\text { Case } \\
\text { No. }\end{array}$} & \multirow{2}{*}{$\begin{array}{l}\text { Age } \\
\text { (yrs), } \\
\text { Sex }\end{array}$} & \multirow[b]{2}{*}{ Localion } & \multirow{2}{*}{$\begin{array}{c}\text { Presentation } \\
\text { (tim e to surgery) }\end{array}$} & \multicolumn{3}{|c|}{ Third Nerve } \\
\hline & & & & Expostre & Resut & Complications \\
\hline $\begin{array}{l}1 \\
2 \\
3\end{array}$ & $\begin{array}{l}56, \mathrm{M} \\
40, \mathrm{~F} \\
37, \mathrm{~F}\end{array}$ & $\begin{array}{l}\text { BA bifurcation } \\
\text { ВA bifurcation } \\
\text { ВÁ bifurcation }\end{array}$ & $\begin{array}{l}\text { SA H (6 days) } \\
\text { indidentil } \\
\text { SA H (24 hrs) }\end{array}$ & $\begin{array}{l}\text { unroofed } \\
\text { unroofed } \\
\text { unroofed, } \\
\text { retracted }\end{array}$ & $\begin{array}{l}\text { trans paresis } \\
\text { trans paralysis } \\
\text { normal }\end{array}$ & $\begin{array}{l}\text { none } \\
\text { none } \\
\text { opposite } \\
\text { third ner'e }\end{array}$ \\
\hline $\begin{array}{l}4 \\
5 \\
6\end{array}$ & $\begin{array}{l}54, M \\
45, F \\
68, M\end{array}$ & $\begin{array}{l}\text { BA bifurcation } \\
\text { BA bifurcation } \\
\text { SCA ВA }\end{array}$ & $\begin{array}{l}\text { indidental } \\
\text { SA H (48 hrs) } \\
\text { SA H (6 mos) }\end{array}$ & $\begin{array}{l}\text { unroofed } \\
\text { dural suture } \\
\text { not dissected }\end{array}$ & $\begin{array}{l}\text { trans paresis } \\
\text { normal } \\
\text { trans paresis }\end{array}$ & $\begin{array}{l}\text { none } \\
\text { none } \\
\text { CSF leak, } \\
\text { hydro- } \\
\text { cephalus }\end{array}$ \\
\hline 8 & $\begin{array}{l}55, F \\
48, F\end{array}$ & $\begin{array}{l}\text { SСД ВВА } \\
\text { SСА ВАA }\end{array}$ & $\begin{array}{l}\text { dizziness } \\
\text { incidental }\end{array}$ & $\begin{array}{l}\text { unroofed } \\
\text { unroofed, } \\
\text { dural suture }\end{array}$ & $\begin{array}{l}\text { trans paralysis } \\
\text { trans paresis }\end{array}$ & $\begin{array}{l}\text { none } \\
\text { none }\end{array}$ \\
\hline
\end{tabular}

In all cases, the initial surgical exposure was made via the pterional transsylvian approach. When the exposure proved inadequate for treatment, more room was obtained by transcavernous removal of the posterior clinoid process and ipsilateral dorsum sellae. In two patients (Cases 2 and 3), a more lateral approach was attempted before using the transcavernous approach; however, this did not help the exposure of the lesion. The lateral approach was made by section of the bridging temporal veins and posterolateral retraction of the temporal lobe as well as subpial resection of the uncus in Case 2 .

There were various reasons why a more proximal exposure of these aneurysms was needed. In Cases 1, 2, and 6, additional space was necessary for temporary proximal BA occlusion. In Cases 1, 3, 5, and 8, the anatomy of the aneurysm and adjacent vessels could not be determined without additional exposure. In Cases 4 and 7, more room was needed for aneurysm clipping.

\section{Operative Technique}

The components of the operative technique used have been described previously by many authors. These include pterional craniotomy, $[6,14]$ intradural removal of the anterior clinoid process, $[9,10]$ entry into the cavernous sinus through its roof medial to the third nerve, $[4,8,11]$ and removal of the posterior clinoid process and exposed dorsum sellae.[4] Pertinent details of the technique used in this series of cases are described as follows.

The standard pterional craniotomy is performed as originally described.[6,14] The dura is elevated over the orbital roof and the greater wing of the sphenoid as far medial as the lateral aspect of the superior orbital fissure and the orbit is skeletonized to that site. The dura is cut to form a flap that is based and retracted over the skeletonized orbit. The sylvian fissure is opened in a lateral-to-medial manner and the carotid and chiasmatic cisterns are opened. This allows gentle retraction of the frontal lobe, resulting in a view of the carotid region and the membrane of Liliequist through the sylvian fissure. Lilie3quist's membrane is opened and the aneurysm site is evaluated. If a more proximal exposure is deemed necessary, the transcavernous approach is undertaken. The desired line of exposure through the cavernous sinus is parallel and medial to the third nerve. To achieve this approach angle, significant lateral retraction of the temporal lobe is usually not necessary and the draining veins from the temporal 
tip are preserved when possible (six of eight cases).

The first step is the intradural removal of the anterior clinoid process,[10] which both defines the carotid artery as it exits the cavernous sinus through the proximal dural ring[3] and exposes the entire roof of the cavernous sinus. The dura overlying the optic canal and anterior clinoid process is excised, staying medial to the dura, which is elevated during the craniotomy, thus avoiding a communication between the subarachnoid and epidural spaces. Initial drilling should unroof approximately $5 \mathrm{~mm}$ of the optic canal. Subsequent drilling of the lateral wall of the optic canal and optic strut free the tip of the anterior clinoid, allowing it to be dissected from its bed with a small curette. The dural roof of the optic canal is then opened in a posteroanterior fashion with the cut curving in a lateral direction until the floor of the optic canal is reached. The incision is continued posteriorly along the floor of the optic canal to the site of dural attachment to the carotid artery. The dura that is adherent to the lateral aspect of the carotid is trimmed, leaving only a small remnant of the dural carotid ring[3] and allowing visualization of the proximal carotid ring[3] and adjacent third nerve. When drilling, an adjacent ethmoid or sphenoid air cell may be entered. Failure to plug these sinus communications at the end of the procedure may lead to postoperative cerebrospinal fluid (CSF) rhinorrhea.[10]

The roof of the cavernous sinus is incised just medial to the third nerve. The course of the nerve is visualized directly by using a sharp cut to open its dural canal from the site of dural penetration to the carotid artery. However, in two of the present cases, the position of the nerve was seen through the canal wall without the need to open it. The anterior incision into the cavernous sinus is started just posterior to the carotid artery medial to the third nerve. As the sinus is entered, hemostasis is achieved by packing alternately with absorbable gelatin sponge soaked in thrombin and with oxidized cellulose. Persistent venous bleeding can be reduced by elevation of the patient's head.[8] The incision is progressively enlarged posteriorly and packing is continued until the posterior clinoid process is encountered. Then, the dural incision is carried medially just anterior to the dorsum sellae as far as possible. This maneuver forms a flap of dura hinged medially that is trimmed away, leaving a triangular opening in the roof of the cavernous sinus. When the opening of the sinus roof is complete, the hemostatic packs are slowly removed and replaced with smaller plugs more precisely directed. Completion of this task leaves a space that is bounded laterally by the third nerve and medial surface of the intracavernous carotid artery, posteriorly by the portion of dorsum sellae, medially by the pituitary gland, and inferiorly by the floor of the sella turcica and adjacent sphenoid bone. Further exposure on each side of the sinus can be obtained. This is achieved on the lateral side by retraction of the wall of the cavernous sinus with a suture placed through the dura beside the third nerve (Cases 5 and 8) or with a self-retaining retractor placed into the opened sinus (Case 3). Medial exposure can be increased by intermittent retraction of the intradural carotid artery.

Removal of the exposed portion of the dorsum sellae and its overlying dura completes the exposure. The bone of the dorsum sellae is drilled away from within the excavated cavernous sinus. While drilling, medial retraction of the intradural carotid artery both improves the exposure and protects the vessel from the rotating shaft of the burr. This was done in Cases 1, 4, 6, and 8. The drilling may cause bleeding from the basilar sinus, which must be packed. Care should be taken in the inferolateral area because undue pressure exerted there could compromise the sixth nerve in Dorello's canal. Drilling the dorsum sellae may cause an opening into the sphenoid sinus that must be plugged to prevent CSF rhinorrhea.

\section{RESULTS}


The transcavernous removal of the posterior clinoid process and a portion of the dorsum sellae extended the exposure proximally along the BA and widened the operative field, allowing enough room to clip the aneurysm in all cases and to place a temporary clip on the proximal BA in Cases 1, 2, and 6.

Visualization of structures near the midline at the level of the floor of the sella turcica was possible. Figure 2 shows an example of the exposure, seen in Case 8, before and after the transcavernous exposure.

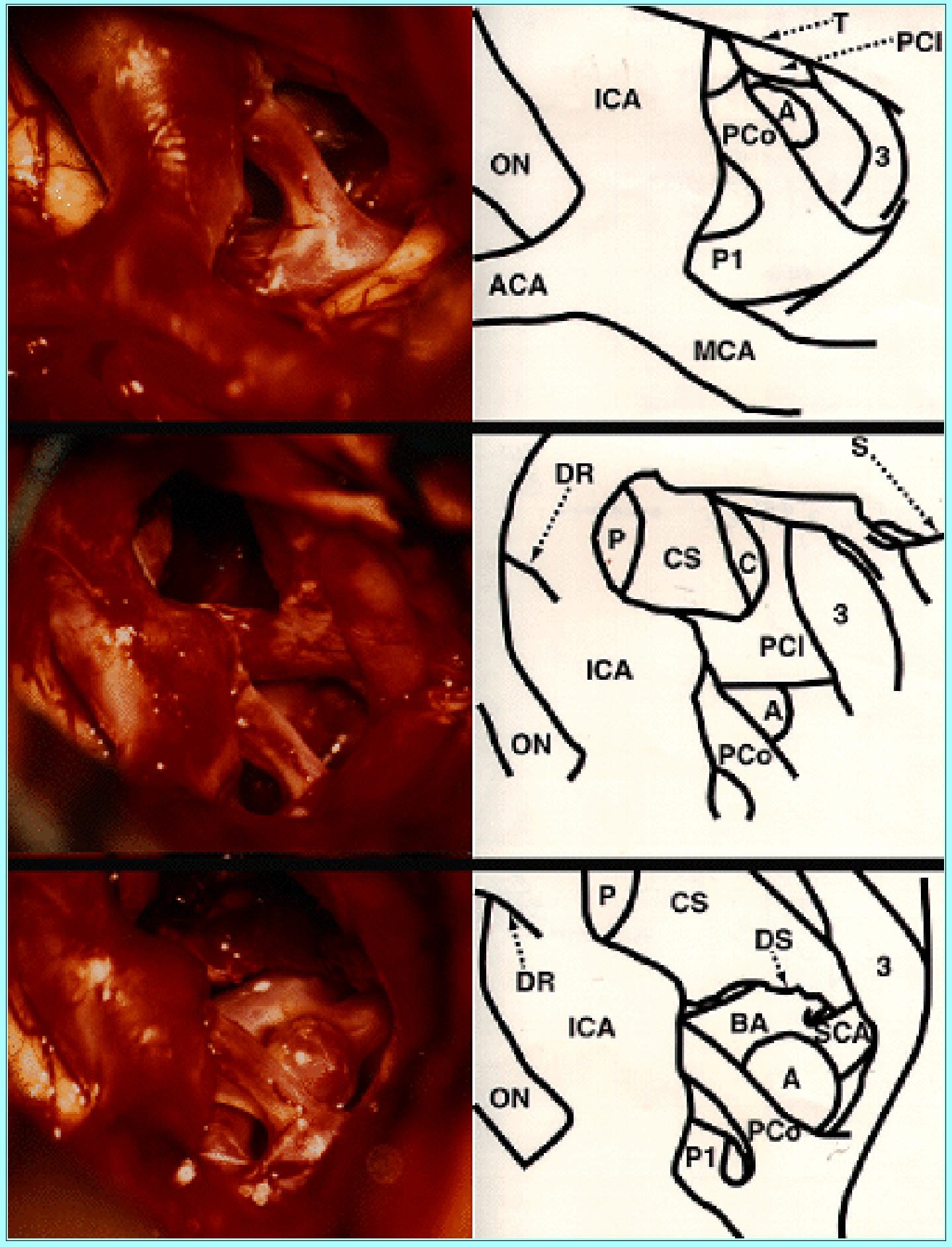

Fig. 2. Case 8. Intraoperative photographs (left) and corresponding drawings (right) of progressive stages of the transcavernous exposure of a BA/SCA aneurysm. Upper: Exposure after the standard pterional approach. Center: The anterior clinoid process has been removed and the cavernous sinus has been excavated. Lower: Completed dissection after removal of the dorsum sellae and its overlying dura. $\mathrm{A}=$ aneurysm; ACA = anterior cerebral artery; $\mathrm{C}=$ cavernous carotid artery; $\mathrm{CS}=$ cavernous sinus; $\mathrm{DR}=$ dural carotid ring; $\mathrm{DS}=$ dorsum 
sellae; $\mathrm{ICA}=$ intradural carotid artery $; \mathrm{MCA}=$ middle cerebral artery; $\mathrm{ON}=$ optic nerve; $\mathrm{P}$ $=$ pituitary gland $\mathrm{PCl}=$ posterior clinoid process $; \mathrm{PCo}=$ posterior communicating artery; $\mathrm{P} 1$ $=$ posterior cerebral artery; $\mathrm{S}=$ suture retracting the lateral edge of the roof of the oculomotor dural canal; $\mathrm{T}=$ free edge of the tentorium and its anterior extension over the anterior clinoid process; [12] $3=$ third nerve.

The patient's pre- and postoperative angiograms are shown in Fig. 3. A schematic representation of the exposure based on the photographs in Fig. 2 is shown in Fig. 4.
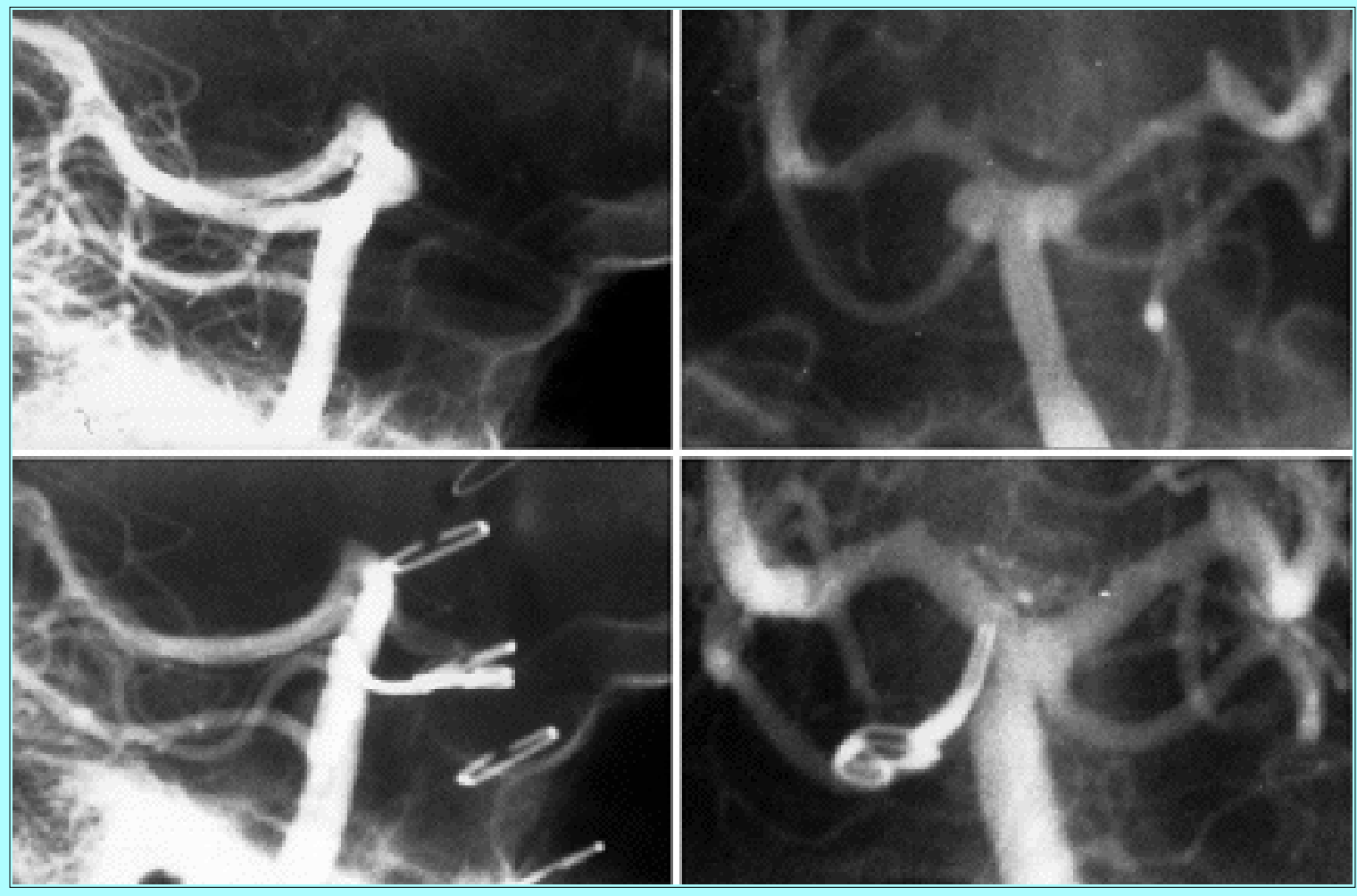

Fig. 3. Case 8. Upper: Preoperative lateral (left) and anteroposterior (right) angiograms. Lower: Postoperative lateral (left) and anteroposterior (right) angiograms.

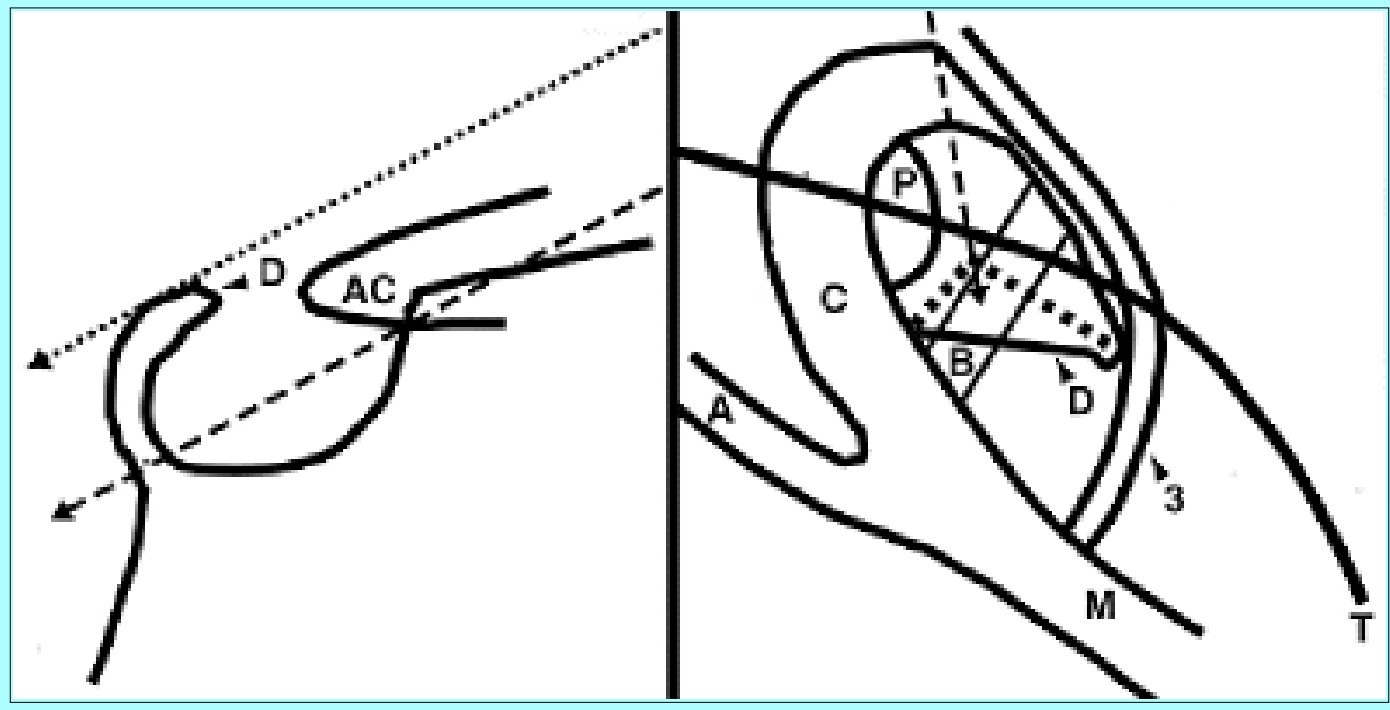

Fig. 4. Schematic representations of the transcavernous approach with the lateral view of the sella turcica (left) shown for orientation and the surgical perspective based on photographs in Fig. 2 (right). Low angles of approach to the distal BA before and after the 
transcavernous procedure are represented by the short-dashed arrow (left) and the long-dashed arrows (right and left), respectively. A lower view is obtained when the angle of approach is increased by frontal lobe retraction or for structures that are located more posterior relative to the dorsum sellae. Before the transcavernous exposure, structures in the diagram that are above (anterior to) the line representing the tentorial edge are covered by the dura and the anterior clinoid process and those between the tentorium and the top of the dorsum sellae by the dural roof of the cavernous sinus; the view into the perimesencephalic cistern is through the triangular area bounded by the top of the dorsum, the carotid artery, and the third nerve. After the transcavernous exposure is completed, a new contiguous triangular area of exposure bounded by the remaining edges of the dorsum is added. These edges are represented by the thick-dashed lines and the triangle is completed by the line representing the top of the removed dorsum. In addition, anterior to this triangle there is a new space in which to work that is formed by the excavation of the cavernous sinus bounded medially by the pituitary gland and the lateral surface of the clinoidal and intradural carotid artery and laterally by the medial surface of the intracavernous carotid artery and the third nerve. The bottom of this space is represented by the dashed arrow that runs in a line from the site where the third nerve crosses the carotid artery to the inferior angle of the dorsum sellae triangle. $\mathrm{A}=$ anterior cerebral artery; $\mathrm{AC}=$ anterior clinoid process; $\mathrm{B}=\mathrm{BA} ; \mathrm{C}=$ internal carotid artery; $\mathrm{D}=$ top of dorsum sellae; $\mathrm{M}=$ middle cerebral artery; $\mathrm{P}=$ pituitary gland; $\mathrm{T}=$ free edge of tentorium; $3=$ third nerve.

A postoperative angiogram was obtained in all cases. Complete aneurysm occlusion was achieved in all but Case 3, in which some residual neck was later partially treated with an endovascular procedure. At 5 -year follow up no change in the residual neck was seen in that case.

With the exception of oculomotor function, the neurological outcome was good in all patients. There were six cases of transient ipsilateral third nerve palsy. In Case 1, the paresis was delayed until 24 hours after surgery. In all cases, third nerve function recovered completely within 3 months of surgery, with recovery occurring most slowly in the two cases in which the patients had complete postoperative paralysis.

Two patients suffered postoperative complications. In Case 3, an oculomotor palsy on the side opposite the exposure resulted from trauma to the third nerve caused by a long aneurysm clip. This nerve did not recover completely. Early postoperative CSF rhinorrhea occurred in Case 6 . Investigation revealed that the communication was through the dorsum sellae. At transsphenoidal exploration, a hole was found in the dorsum sellae at the level of the floor of the sella turcica. This was plugged with fascia, but the leak recurred 6 weeks later. At that time the leak was successfully treated by repacking the hole and the patient's progressive hydrocephalus was treated with placement of a ventriculoperitoneal shunt.

\section{DISCUSSION}

Good results of surgical treatment for distal BA aneurysms were first obtained using the subtemporal approach.[5] Subsequently, excellent results were also obtained using the pterional approach developed by Yasargil.[15] The advantages of the pterional over the subtemporal procedure include better bilateral visualization of major blood vessels and perforating vessels because of the more anterior approach, less temporal lobe retraction, less oculomotor nerve trauma, and, because it is an extension of the approach used to treat the more common anterior circulation aneurysms, greater familiarity for most surgeons. 
However, some distal BA aneurysms are poorly visualized when this approach is used.

Basilar artery aneurysms situated below the level of the posterior clinoid process may be inaccessible via the standard pterional transsylvian approach. Angiographic evidence indicates that 14 to $19 \%$ of distal BA lesions are below the level of the posterior clinoid process. $[7,13]$ In the surgical series presented by Samson and colleagues,[13] two of 15 BA bifurcation aneurysms and one of three SCA aneurysms were deemed too low to be treated by the pterional approach. The tracings of angiograms of those cases are similar to those presented in the present series. In Yasargil's series[15] of 50 BA bifurcation aneurysms, two could not be exposed initially because of an intervening posterior clinoid process.

Aneurysms that are hidden from view by the posterior clinoid process or dorsum sellae when approached by the pterional route will require additional exposure for treatment. Yasargil[15] successfully clipped two hidden aneurysms in his series after removal of the posterior clinoid process, which was accomplished with a high-speed drill. Dolenc, et al.,[4] described a transcavernous approach that further enlarges the exposure below the posterior clinoid process. The technique described in the present paper is a modification of the Dolenc procedure that provides the same exposure. Using a transcavernous technique, the BA can be exposed down to the level of the floor of the sella turcica at the dorsum close to the midline. It also widens the exposure in a pyramidal shape from an apex at the anterior clinoid process to a base at the site of the removed dorsum sellae (Fig. 4). Exposure of the BA below the level of the sella floor requires a subtemporal[5] or cranial base approach.[1]

Removal of the anterior clinoid process is the initial step in the transcavernous approach. In the present series this step was performed by an intradural approach rather than by the extradural procedure used by others. $[1,2,4,16]$ The choice of an intradural anterior clinoid removal was influenced by a number of factors. These factors include the benefit of an intraoperative determination of the need for a more extensive exposure, the ease and safety of the intradural procedure, and the ability to achieve a watertight closure of the dura mater at the end of the surgery. Some discussion of these factors follows. Using the intradural approach, the site of the aneurysm can be inspected and removal of the anterior clinoid process can be avoided if the transcavernous approach is found to be unnecessary. If additional exposure is necessary, the amount of bone dissection needed to remove the anterior clinoid is much less extensive when using the intradural rather than the extradural approach. Also, intradural anterior clinoid removal is easy to learn because the important anatomical structures that serve as guides to the bone removal can be visualized directly. These structures include the intradural carotid artery, optic nerve, and anterior clinoid process. The protection that the dura theoretically provides to these intradural structures during the extradural anterior clinoid removal[16] may not be significant because we have not found a higher complication rate by using the intradural procedure.[10] Finally, the intradural approach to anterior clinoid removal allows an easy watertight closure of the dura that was opened only over the convexity surface of the brain. After the extradural procedure, Day and associates[2] state that a fascial patch graft may be necessary to repair the dural opening.

Transient third nerve dysfunction occurred in six of the eight patients undergoing transcavernous procedures in this series, in seven of 11 patients reported by Dolenc, et al.,[4] but in only three of 10 patients reported by Day and associates.[1] The incidence was $50 \%$ or less in cases in which the standard pterional approach was used.[6,13,15] A higher incidence in the transcavernous cases may be due to increased manipulation of the nerve caused by unroofing its canal.

CONCLUSIONS 
The pterional transsylvian transcavernous approach to the distal BA allows increased exposure of the vessel at, or just below, the level of the posterior clinoid process. It may extend the exposure to the level of the floor of the sella turcica. The added exposure is most useful for treating low-lying distal BA aneurysms or for treating aneurysms that are located higher but require simultaneous temporary proximal BA clipping. Use of this technique allows clipping of aneurysms previously thought to be inaccessible when using the pterional approach. The technique is a relatively easy extension of the standard pterional approach. Sacrifice of the bridging veins from the temporal lobe is seldom necessary or helpful for the exposure. Transient postoperative ipsilateral third nerve dysfunction is common in these cases.

\section{References}

1. Day JD, Fukushima T, Giannotta SL: Cranial base approaches to posterior circulation aneurysms. J Neurosurg 87:544-554, 1997

2. Day JD, Giannotta SL, Fukushima T: Extradural temporopolar approach to lesions of the upper basilar artery and infrachiasmatic region. J Neurosurg 81:230-235, 1994

3. Dolenc VV: Anatomy and Surgery of the Cavernous Sinus. New York: Springer-Verlag, 1989, p 4

4. Dolenc VV, Skrap M, Sustersic J, et al: A transcavernous-transsellar approach to the basilar tip aneurysms. Br J Neurosurg 1:251-259, 1987

5. Drake CG: The treatment of aneurysms of the posterior circulation. Clin Neurosurg 26:96-144, 1979

6. Heros RC, Lee SH: The combined pterional/anterior temporal approach for aneurysms of the upper basilar complex: technical report. Neurosurgery 33:244-251, 1993

7. Krayenbühl HA, Yasargil MG: Cerebral Angiography, ed 2. London: Butterworths, 1968, p 74

8. Matsuoka Y, Hakuba A, Kishi H, et al: Direct surgical treatment of intracavernous internal carotid artery aneurysms: report of four cases. Surg Neurol 26:360-364, 1986

9. Nutik SL: Exposure of proximal intracranial carotid artery. J Neurosurg 70:656, 1989 (Letter)

10. Nutik SL: Removal of the anterior clinoid process for exposure of the proximal intracranial carotid artery. J Neurosurg 69:529-534, 1988

11. Ohmoto T, Nagao S, Mino S, et al: Exposure of the intracavernous carotid artery in aneurysm surgery. Neurosurgery 28:317-324, 1991

12. Ono M, Ono M, Rhoton AL Jr, et al: Microsurgical anatomy of the region of the tentorial incisura. J Neurosurg 60:365-399, 1984

13. Samson DS, Hodosh RM, Clark WK: Microsurgical evaluation of the pterional approach to aneurysms of the distal basilar circulation. Neurosurgery 3:135-141, 1978

14. Yasargil MG: Microneurosurgery. New York: Thieme, 1984, Vol 1, pp 215-234

15. Yasargil MG: Microneurosurgery. New York: Thieme, 1984, Vol 2, pp 253-256

16. Yonekawa Y, Ogata N, Imhof HG, et al: Selective extradural anterior clinoidectomy for supra- and 
Manuscript received April 28, 1998.

Accepted in final form July 24, 1998.

Address reprint requests to: Stephen L. Nutik, M.D., Ph.D., Department of Neurosurgery, Kaiser Foundation Hospital, 1150 Veteran's Boulevard, Redwood City, California 94063. 